\title{
THE DISTRIBUTION OF CHF WITHIN SOUTHERN WEST VIRGINIA
}

Frank Annie ${ }^{1}$, Muhammad Yasin $^{1}$, and Aravinda Nanjundappa ${ }^{1}$

${ }^{1}$ Affiliation not available

November 11, 2020

THE DISTRIBUTION OF CHF WITHIN SOUTHERN WEST VIRGINIA

Frank H Annie, $\mathrm{PhD}^{1}$; Muhammad Yasin, $\mathrm{MD}^{2}$, Aravinda Nanjundappa, $\mathrm{MD}^{2}$;

1. CAMC Health Education and Research Institute

3200 MacCorkle Ave. SE, Charleston, WV 25304.

2. CAMC Vascular Center of Excellence, Charleston Area Medical Center.

3200 MacCorkle Ave SE, Charleston, WV 25304

Study Locations:

Charleston Area Medical Center, 3100 McCorkle Ave SE, Charleston, WV, 25302 and Charleston Area Medical Center Research Institute and Center for Clinical Sciences Research, 3200 McCorkle Ave SE, Charleston, WV, 25302

Correspondence:

Frank Annie M.A; MPA, PhD

Research Scientist

CAMC Health Education and Research Institute

3200 MacCorkle Ave. SE,

Charleston, WV 25304

Phone 304-388-9921

Fax: 304-388-9921

Email: Frank.H.Annie@camc.org

Total word count: 593

Author Disclosure Block: None

Key words: Access, CHF

Running Title: The Distribution of CHF

Total Number of Tables and Figures: Figures 1

Per the United States (U.S) Census Bureau, rural areas are geographic designations excluding all population, housing, and territory included within an urbanized area or cluster (1). Approximately $20 \%$ of the U.S. 
population lives in these rural designations. The literature reports that rural populations face more barriers associated with access and quality of care compared with urban groups. Cultural attitudes, access difficulty, and absence of services are a few of several contributing factors (2).

However, there is little evidence that specifically addresses the needs of rural patients suffering from congestive heart failure $(\mathrm{CHF})$. A number of factors can cause CHF, including coronary artery disease, valvular disease, and systemic hypertension. Poor health literacy, roughly defined as the degree of difficulty an individual has while attempting to obtain, process, and understand basic health information and services, is associated with earlier heart failure hospitalization and all-cause mortality in rural patients with CHF in the U.S. (3). Elderly U.S. veterans who reside in rural designations are more vulnerable to delayed CHF treatment due to lack of transportation (4).

Whether patients with CHF who reside in rural designations struggle to comprehend information due to culturally-based reservations or lack resources available to their urban counterparts, it is important to identify those who require improved access so that their perspective and needs can be better assessed. Appalachia is a distinct, non-homogenous region within the U.S. that is comprised of 13 states, in which $42 \%$ reside in rural areas or clusters (5). We conducted a retrospective analysis of CHF cases from 2005-2016 obtained from our Charleston Area Medical Center (CAMC) data warehouse in Charleston, West Virginia. Using a Hot Spot Analysis, we aimed to identify patients with CHF from rural territories and housing who have limited access. After the data were analyzed $(\mathrm{n}=22,404)$, patients were identified and examined using Arch 10.8 and geocoded. To investigate any potential spatial relationships, and a Hot Spot Analysis was performed. We controlled for population in order to understand the areas in which CHF had statistical significant hot and cold zones.

The results suggest within (Figure 1) that areas in which CHF cases are further from major hospitals in Southern West Virginia appear to have increased cold spots within these zones. These zones are illustrated in bright blue and have a $(\mathrm{P}=0.001)$. These results suggest access and health care resources are still a significant issue within Southern West Virginia, as illustrated in (Figure 1). These at-risk zones are outside the baseline 5 miles radius of the majority of substantial statistical zones. These results also suggest that further access in the form of CHF clinics and other households of access is essential.

Figure Legend

Figure 1 - Hot Spot Analysis of Congestive heart failure (CHF) $(\mathrm{n}=22,404)$ 


\section{Analysis of Congestive heart failure (CHF) $(n=22,404)$}

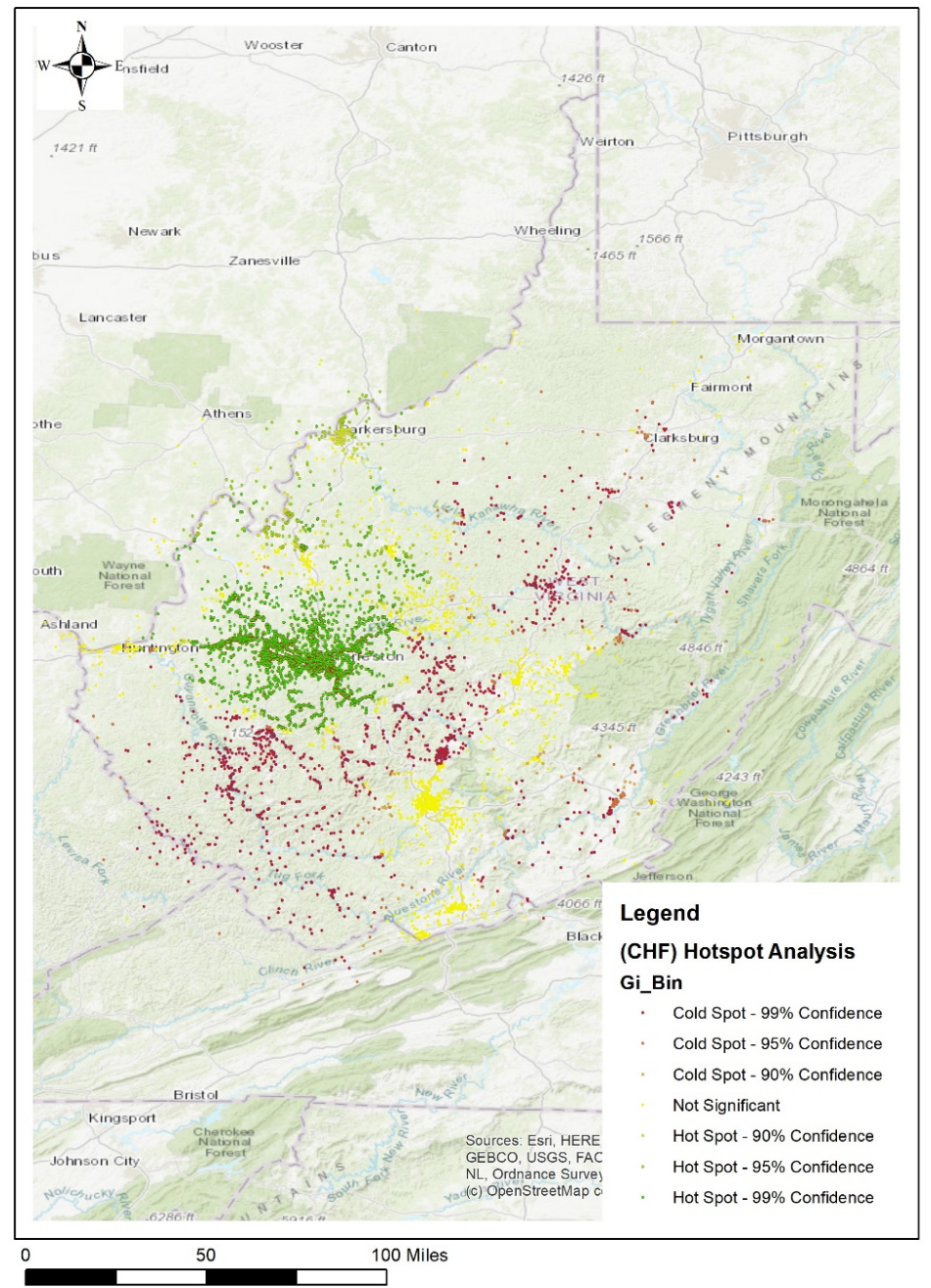

\section{References}

1. Ratcliffe M, Burd C, Holder H, Fields A. Defining Rural at the US Census Bureau ACSGEO-1 . Washington, DC: US Census Bureau; 2016.

2. Douthit N, Kiv S, Dwolatzky T, Biswas S. Exposing some important barriers to health care access in the rural USA. Public Health. 2015;129(06):611-620.

3. Moser, D. K., Robinson, S., Biddle, M. J., Pelter, M. M., Nesbitt, T. S., Southard, J., ... Dracup, K. (2015). Health literacy predicts morbidity and mortality in rural patients with heart failure. Journal of Cardiac Failure, 21(8), 612-618. doi:10.1016/j.cardfail.2015.04.004

4. Muus KJ, Knudson A, Klug MG, Gokun J, Sarrazin M, Kaboli P. Effect of post-discharge follow-up care on re-admissions among US veterans with congestive heart failure: a rural-urban comparison. Rural Remote Heal. 2010;10(2):1447.

5. The Appalachian Region. The Appalachian Region - Appalachian Regional Commission. https://www.arc.gov/appalachian_region/TheAppalachianRegion.asp. Accessed April 22, 2020. 